Cristiane Flores Vilarta

\title{
Prevalência de hipovitaminose D em pacientes transplantados renais
}

Dissertação apresentada à Faculdade de Medicina da Universidade de São Paulo para a obtenção do título de Mestre em Ciências

Programa de: Nefrologia

Orientadora: Dra. Vanda Jorgetti

São Paulo

2010 
Cristiane Flores Vilarta

\section{Prevalência de hipovitaminose D em pacientes transplantados renais}

Dissertação apresentada à Faculdade de Medicina da Universidade de São Paulo para a obtenção do título de Mestre em Ciências

Programa de: Nefrologia

Orientadora: Dra. Vanda Jorgetti

São Paulo

2010 
Dados Internacionais de Catalogação na Publicação (CIP)

Preparada pela Biblioteca da

Faculdade de Medicina da Universidade de São Paulo

Creprodução autorizada pelo autor

\section{Vilarta, Cristiane Flores}

Prevalência de hipovitaminose D em pacientes transplantados renais / Cristiane Flores Vilarta. -- São Paulo, 2010.

Dissertação(mestrado)--Faculdade de Medicina da Universidade de São Paulo. Programa de Nefrologia.

Orientadora: Vanda Jorgetti.

Descritores: 1.Vitamina D 2.Hipovitaminose D 3.Transplante de rim 4.Prevalência 5.Raios ultravioleta 6.Protetores de raio solares 7.Recomendações nutricionais 8.Hormônio paratireóideo

USP/FM/DBD-482/10 


\section{Dedicatória}

À Profa. Dra. Vanda Jorgetti, pela dedicação irrestrita, além de conduzir-me com sua experiência e simplicidade para realização desta pesquisa. 


\section{Agradecimentos}

À minha mãe, por estar incansavelmente ao meu lado.

À minha irmã, pelo cuidado incalculável nos momentos necessários.

Ao meu pai, por me ensinar a seguir sempre em frente.

Ao meu filho Joaquim, tão pequeno, mas que já me ensina a valorizar o que tenho na vida.

Ao Gui, meu marido querido, por todo amor e acolhimento indispensável nas minhas solicitações de apoio e carinho além do incentivo sempre oportuno.

À minha tia Neuzinha, pelas palavras precisas que facilitaram o meu percurso.

Aos meus avós, pelo amor e por sempre acreditarem em mim.

Às amigas Ana Amélia Fayer, Juliana Vinagre e Ana Felipe, pela contribuição direta, tanto nas interlocuções como nos meus pedidos de socorro.

Ao Wagner Vasques Dominguez e a Luciene Machado dos Reis, pelas correções, pelo apoio e pela ajuda inestimável.

Aos meus colegas da Pós-Graduação e do Laboratório de Fisiopatologia Renal pelos bons momentos.

Aos pacientes pela paciência e disponibilidade na participação desse estudo.

À Fundação de Amparo e Pesquisa do Estado de São Paulo (FAPESP), pelo auxilio financeiro. 


\section{SUMÁRIO}

\section{RESUMO}

\section{SUMMARY}

$1 \quad$ INTRODUÇÃO .................................................................... 1

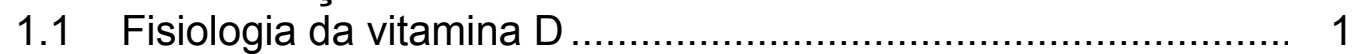

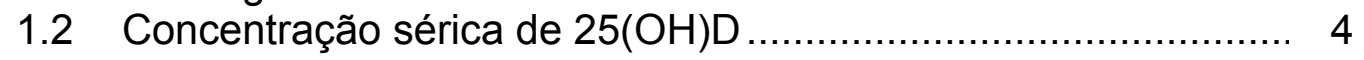

1.3 Transplante renal ...................................................... 12

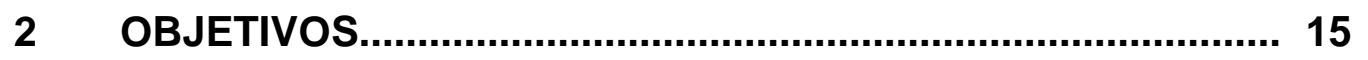

3 PACIENTES E MÉTODOS ................................................... 16

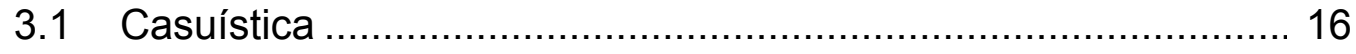

3.2 Tipo de estudo ............................................................. 18

3.3 Avaliação laboratorial ....................................................... 18

3.4 Avaliação dos hábitos de exposição solar ............................... 19

3.5 Inquérito dietético .......................................................... 19

3.6 Comissão de ética.......................................................... 19

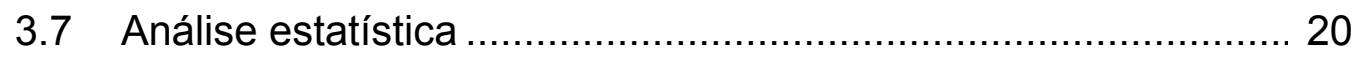

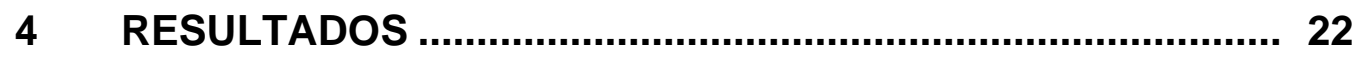

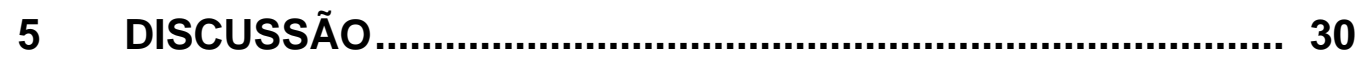

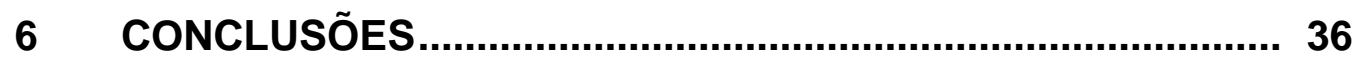

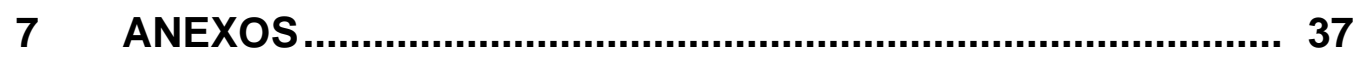

8 REFERÊNCIAS ........................................................... 41 


\section{RESUMO}

Vilarta CF: Prevalência de hipovitaminose $\mathrm{D}$ em pacientes transplantados renais [dissertação]. São Paulo: "Faculdade de Medicina, Universidade de São Paulo"; 2010. 48 p.

Inúmeros estudos têm demonstrado elevada prevalência de hipovitaminose D (deficiência/insuficiência de $25(\mathrm{OH}) \mathrm{D}$ ) em indivíduos normais e em pacientes com e sem doença renal. Como os pacientes transplantados renais têm maior risco de desenvolver câncer de pele, são orientados a evitar exposição ao sol e usar filtro solar. A combinação de doença renal crônica (DRC) e menor exposição ao sol contribuem para que esses pacientes desenvolvam hipovitaminose $\mathrm{D}$, o que pode piorar ou favorecer o desenvolvimento de doença óssea.

O objetivo desse estudo foi avaliar a concentração sérica de $25(\mathrm{OH}) \mathrm{D}$ e a prevalência de hipovitaminose $D$ em uma amostra representativa $(N=149)$ de pacientes transplantados renais do Hospital das Clinicas da Universidade de São Paulo. Avaliamos ainda se a hipovitaminose poderia ser atribuída a menor exposição ao sol ou ingestão insuficiente de alimentos fontes. Comparamos os níveis séricos de $25(\mathrm{OH}) \mathrm{D}$ desses pacientes com o de indivíduos normais. Hipovitaminose $\mathrm{D}$, definida pelos níveis séricos de 25(OH)D menores que $30 \mathrm{ng} / \mathrm{ml}$, foi observada em $79 \%$ dos pacientes transplantados e o principal fator determinante foi a menor exposição ao sol.Os níveis séricos de creatinina e de paratormônio (PTH) foram significativamente mais elevados nos pacientes com hipovitaminose quando comparados aos com níveis normais de 25(OH)D. Observamos uma 
correlação inversa dos níveis séricos de $25(\mathrm{OH}) \mathrm{D}$ com os de paratormônio $(r=-0,24 ; p<0,03)$. A prevalência de hipovitaminose $D$ foi maior nos pacientes transplantados que nos indivíduos normais. Os níveis séricos de creatinina e PTH foram mais elevados nos transplantados, enquanto os de Ca, $\mathrm{P}$ e albumina menores que dos indivíduos normais.

Em conclusão: A hipovitaminose $D$ é freqüente nos pacientes transplantados renais e orientação dietética, exposição solar curta e regular ou mesmo a suplementação com vitamina $D$ seriam medidas simples para assegurar níveis adequados dessa vitamina. 


\section{SUMMARY}

Vilarta CF: Prevalence of hypovitaminosis D in kidney transplant patients [dissertation].São Paulo: "Faculdade de Medicina, Universidade de São Paulo"; 2010. 48 p.

Recent epidemiological studies have shown a high prevalence vitamin $D$ deficiency in normal population and in patients with and without kidney diseases. In addition, kidney transplant patients are at higher risk for skin cancer, so they are advised to avoid sun and use sunscreen. Because of the combination of chronic kidney disease (CKD) and sun avoidance, kidney transplant patients are at high risk for developing hypovitaminosis $\mathrm{D}$.

We evaluated serum 25 vitamin $D$ levels in a representative sample $(N=$ 149) of kidney transplant patients from the University of São Paulo Transplant Unit. Our objectives were to determine the prevalence of hypovitaminosis D, comparing them to normal volunteers, as well as, to identify the factors that could be associated with this decrease in serum 25 vitamin $D$, such as sun exposure and dietary habits. Hypovitaminosis D, defined by serum levels $<30 \mathrm{ng} / \mathrm{mL}$, was found in $79 \%$ of kidney transplant patients, and the main associated factor was low sun exposure. Patients that presented hypovitaminosis $\mathrm{D}$ had higher serum creatinine and parathormone (PTH) levels. Serum 25 vitamin D correlated with serum PTH $(r=-0.24$; $p=0.03$ ). When compared to normal volunteers, renal transplant patients presented a higher prevalence of hypovitaminosis $D$, as well as low serum calcium, phosphate albumin, and higher creatinine, and PTH. Our results confirm a high prevalence of hypovitaminosis $\mathrm{D}$ in renal transplant patients. 
In conclusion, hypovitaminosis $D$ is frequent in kidney transplant patients, therefore dietary orientation, short or regular sun exposure, and vitamin D supplementation are important determinants of vitamin D status. 


\section{INTRODUÇÃO}

\subsection{Fisiologia da vitamina D}

A vitamina $D$ é um dos hormônios mais antigos, se não o mais antigo, existente na terra. Emilianii Huxleyi um fitoplâncton encontrado no oceano Atlântico há pelo menos 750 milhões de anos, produz uma grande quantidade de ergosterol, precursor da vitamina $\mathrm{D}_{2}{ }^{1}$.

A principal função da vitamina $D$, nos vertebrados, é manter a concentração sérica de cálcio e fósforo dentro de níveis normais. Sua concentração sérica depende de produção endógena, através da exposição solar, e exógena, obtida da dieta. A maior fonte natural desta vitamina está nos peixes gordurosos como o salmão e no óleo de peixe incluindo óleo de fígado de bacalhau. A vitamina D também pode ser encontrada em alimentos suplementados, como leite e cereais ${ }^{2}$.

A vitamina $D$ vinda de plantas e leveduras recebe a denominação de vitamina $D_{2}$, e aquela encontrada no óleo de peixe e produzida pela pele é designada vitamina $D_{3}$. A diferença entre elas está na dupla ligação entre o C22 e C23, e um grupo metil no $C 24$ na vitamina $D_{2}{ }^{2}$.

Durante a exposição solar, os fótons ultravioleta (UV-B) estimulam a fotólise do 7-dehidroxicolesterol (7-DHC) na epiderme, até a formação da pré-vitamina $D_{3}$, que pode ser termicamente isomerizada a vitamina $D_{3}$ ou absorver a radiação e formar isômeros inertes. Isto ocorre quando os 
comprimentos de onda são mais curtos, entre 280 e $315 \mathrm{~nm}^{2}$. Até duas horas após a exposição solar, $50 \%$ da pré-vitamina $D_{3}$ é convertida em vitamina $D_{3}$. O aumento do tempo de exposição solar não favorece maior produção de vitamina $D_{3}$. Além do mais, sua síntese pode diminuir pelo uso de filtro solar e pela melanina, já que ambos absorvem os fótons ultravioleta $^{2,3}$.

As vitaminas $D_{2}$ e $D_{3}$, ligam-se a proteína transportadora da vitamina D (DBP), com a qual apresentam alta afinidade. Ambas são transportadas até o fígado para serem transformadas em 25(OH)D. Essa transformação é regulada pela enzima 25-vitaminaD-hidroxilase (também conhecida como CYP27A1, CYP3A4, CYP2R1, CYP2J3) presente na mitocôndria hepática. A 25(OH)D é a principal forma circulante da vitamina $D$. Um aumento na produção de vitamina $D_{3}$ cutânea ou maior ingestão de vitamina $D\left(D_{2}\right.$ e $\left.D_{3}\right)$ resultará na elevação dos níveis circulantes da 25(OH)D. Portanto, os níveis séricos da 25(OH)D são marcadores de carência, deficiência ou intoxicação por vitamina $D^{2,4}$.

A 25(OH)D liberada do fígado, se liga novamente a DBP e é transportada até os rins. Com auxílio da megalina, proteína presente na membrana plasmática das células do túbulo renal, o complexo DPB/25(OH)D é reconhecido e transportado para dentro da célula. Uma vez no interior, a 25(OH)D é liberada, sofre ação da enzima 25-vitaminaD-1-alfahidroxilase presente nas mitocôndrias, sendo convertida em 1,25 dihidroxivitamina $\mathrm{D}\left(1,25(\mathrm{OH})_{2} \mathrm{D}\right)$. Esta enzima também já foi encontrada em queratócitos, testículos, cérebro, células ósseas, macrófagos, placenta, 
células prostáticas, células cancerígenas de cólon e em ilhotas pancreáticas, porém sua função nesses tecidos ainda é pouco conhecida e essa produção extrarenal de $1,25(\mathrm{OH})_{2} \mathrm{D}$ é pouco regulada ${ }^{4,5}$.

Há também outra enzima, a 24-hidroxilase (CYP24), que converte a 25(OH)D e a 1,25(OH $)_{2} \mathrm{D}$ em 24,25-dihidroxivitamina D e 1,24,25trihidroxivitamina D, respectivamente. Estes produtos são considerados biologicamente inertes. Embora mais de cinqüenta metabólitos diferentes da vitamina $D$ tenham sido identificados, a $1,25(\mathrm{OH})_{2} \mathrm{D}$ é considerada a forma ativa da vitamina $D$ responsável pela manutenção da homeostase do cálcio e fósforo ${ }^{2,3}$. Esse metabólito interage com o receptor de vitamina D (VDR), presente em praticamente em todas as células do organismo. O receptor e a $1,25(\mathrm{OH})_{2} \mathrm{D}$ formam um complexo com o receptor $\mathrm{X}$ do ácido retinóico (RXR) no núcleo das células, e esse complexo $\left(1,25(\mathrm{OH})_{2} \mathrm{D}-\mathrm{VDR}-\mathrm{RXR}\right)$ ligase ao elemento responsivo de vitamina $D$ (VDRE). No intestino delgado, esse complexo atua nos canais de cálcio, permitindo a entrada desse elemento nas células. A $1,25(\mathrm{OH})_{2} \mathrm{D}$ também aumenta a absorção de fósforo nas células intestinais. O mecanismo de ação da $1,25(\mathrm{OH})_{2} \mathrm{D}$ é semelhante ao dos hormônios esteróides o que faz com que esse metábolito seja considerado um hormônio² .

As células da paratireóide possuem VDR que respondem a $1,25(\mathrm{OH})_{2} \mathrm{D}$ pela diminuição da expressão do gene do hormônio da paratireóide $(\mathrm{PTH})$, reduzindo sua síntese e secreção ${ }^{4}$. Quando o cálcio sérico diminui, há uma elevação no nível sérico de $\mathrm{PTH}$, que provoca um aumento na conversão renal de $25(\mathrm{OH}) \mathrm{D}$ em $1,25(\mathrm{OH})_{2} \mathrm{D}$. A própria 
25(OH)D suprime a síntese de PTH atuando, também, via receptor VDR ${ }^{7}$. Segersten et al demonstraram a expressão de 1-alfa-hidroxilase em células paratireoideanas normais. Essa mesma enzima apresenta expressão intensa em células paratireoideanas, oriundas de adenomas e de hiperplasia difusa e reduzida nas células de câncer paratireoideano. Esses achados sugerem que ocorre produção local de $1,25(\mathrm{OH})_{2} \mathrm{D}$ nas paratireóides e que a enzima provavelmente atua regulando o crescimento celular ${ }^{5}$.

Evidências recentes sugerem que um fator conhecido como fator de crescimento fibroblasto (FGF23), sintetizado principalmente nos osteócitos e osteoblastos, participa da homeostase do fósforo. Quando o FGF23 está elevado, há uma internalização do co-transportador sódio-fósforo no rim e intestino, desencadeando fosfatúria e menor absorção intestinal de fosfato. Esse fator inibe a atividade da CYP27B1, reduzindo a produção de $1,25(\mathrm{OH})_{2} \mathrm{D}$ e diminuindo mais ainda a absorção intestinal de fosfato ${ }^{3}$.

\subsection{Concentração sérica de 25(OH)D}

A concentração sérica de $25(\mathrm{OH}) \mathrm{D}$ é usada como o indicador dos níveis de vitamina $\mathrm{D}$ no organismo. O primeiro método, certificado e empregado para quantificar a $25(\mathrm{OH}) \mathrm{D}$ sérica, data de $1978^{7}$. O autor utilizou como técnica, a cromatografia liquida de alta performance (HPLC) que, até recentemente, era a técnica padrão para esse tipo de análise. Atualmente a cromatografia liquida (LC-MS) é considerada a técnica mais precisa. Vale ressaltar que até o presente momento nem as técnicas mais 
sofisticadas (HPLC e LC-MS) conseguem sistematicamente analisar separadamente a $25(\mathrm{OH}) \mathrm{D}_{2}$ e $25(\mathrm{OH}) \mathrm{D}_{3}{ }^{8}$. Tanto o HPLC quanto LC-MS necessitam de equipamentos caros e disponíveis em poucos centros. Nos últimos anos, outras técnicas como, por exemplo, radioimunoensaio (RIA) e quimiluminescência foram desenvolvidas e têm sido cada vez mais utilizadas. A grande variabilidade entre os diferentes métodos é motivo de preocupação, pois leva a interpretações distintas quanto aos níveis séricos normais, bem como no seguimento dos pacientes quando se institui uma determinada terapêutica.

Em 1989 foi criado um comitê internacional com sede em Londres: The Vitamin D International External Quality Assessement Scheme (DEQAS), que monitoriza os diferentes métodos de dosagem da 25(OH)D e da $1,25(\mathrm{OH})_{2}$ D. São 180 participantes de 23 países, e os resultados são publicados regularmente e podem ser acessados no site: http://www.deqas.org ${ }^{9}$. Recentemente Carter et al , um dos responsáveis pelo comitê, publicou resultados comparando diferentes kits comerciais, ou seja DiaSorin RIA, DiaSorin Liason, IDS RIA, IDS OCTEIA, Nichols Advantage com as dosagens por HPLC e LC-MS. Nesse artigo a concentração de $25(\mathrm{OH}) \mathrm{D}$ nos diferentes kits citados foi respectivamente: 39,$2 ; 36,8 ; 36,4 ; 47,3 ; 58,9 ; 42,6$ e 34,0 nM/L. Essas variações são conseqüências de vários fatores, entre eles o tipo de extração empregada ${ }^{10}$. Glendenning et al demonstraram que o método RIA Diasorin e IDS, e quimiluminescência da Nichols superestimam a concentração de $25(\mathrm{OH}) \mathrm{D}_{3}$ e subestimam a concentração de $25(\mathrm{OH}) \mathrm{D}_{2}$ comparados ao método HPLC ${ }^{11}$. 
Dessa forma, estes dois métodos fornecem informações sobre as concentrações da $25(\mathrm{OH}) \mathrm{D}$, sem diferenciar os dois metabólitos.

Embora os níveis séricos de $25(\mathrm{OH}) \mathrm{D}$ na população normal, ainda não tenham sido definitivamente estabelecidos, existe um consenso que aceita como adequado, valores de 30 a $50 \mathrm{ng} / \mathrm{mL}$. São considerados insuficientes, quando sua concentração está entre 15 e 30 ng/mL e deficientes se estiver abaixo de $15 \mathrm{ng} / \mathrm{mL}^{12}$.

Segundo diretrizes americanas, a recomendação de vitamina $D_{2}$ e $D_{3}$ para manutenção da integridade óssea é de 200 Ul/dia para crianças e adultos jovens, $400 \mathrm{UI} /$ dia para adultos de 51 a 70 anos e $600 \mathrm{UI} /$ dia para indivíduos com idade superior a $70 \operatorname{anos}^{13}$. Porém, diversos estudos concordam que sem adequada exposição solar, tanto crianças como adultos necessitam de aproximadamente 800 a 1000 UI por dia ${ }^{14}$.

A exposição à luz solar é a melhor fonte de vitamina $D$, já que a pele tem uma grande capacidade de produção. Crianças e adultos de todas as idades podem obter níveis adequados de vitamina $D$ através da exposição solar. Para adultos jovens, uma exposição mínima do corpo, pode equivaler a uma dose oral entre 10.000 e 25.000 Ul de vitamina $D^{13}$.

No entanto, diversos fatores podem diminuir a produção cutânea dessa vitamina. Negros requerem uma maior exposição solar para sintetizar a mesma quantidade do que brancos, já que a melanina absorve os fótons UV, diminuindo a conversão do 7-DHC em previtamina $\mathrm{D}_{3}{ }^{15}$.

A idade também diminui a concentração de 7-DHC na pele. 
Aparentemente, a eficiência da pele para sintetizar vitamina D diminui com a idade. Quando comparado a adultos jovens, pessoas acima de 70 anos produzem $30 \%$ menos vitamina $D_{3}$. Porém, dependendo do estilo de vida do idoso, ou seja, se são ativos e se expõem ao sol, conseguem manter níveis de vitamina $D$ similares aos de pessoas jovens ${ }^{16,17}$.

Com a redução da espessura da pele, causada tanto pela idade avançada quanto pelo uso de drogas como, por exemplo, de corticosteróides, observa-se diminuição desta vitamina ${ }^{18}$.

Como a atmosfera é dinâmica, mudanças rápidas ocorrem na camada de ozônio, gás que absorve radiação UVB. Esse gás também sofre influencia das estações do ano e das latitudes, como por exemplo, atinge um ápice na primavera e um mínimo no outono. Nas altas latitudes, entre os meses de novembro a fevereiro, a luz do sol diminui consideravelmente sua capacidade para produzir vitamina $D_{3}$. Isto torna necessária a suplementação para prevenir deficiência dessa vitamina. Crianças e adultos expostos aos raios UVB durante a primavera, verão e outono, nas baixas latitudes, conseguem estocar quantidades suficientes de vitamina D para usá-la durante o inverno. Vale lembrar que o uso de protetor solar fator 8 reduz a produção cutânea de vitamina $D_{3}$ em $95 \%{ }^{15}$.

Os níveis séricos de $25(\mathrm{OH}) \mathrm{D}$ são mais elevados nos indivíduos de países escandinavos quando comparados aos dos países do Mediterrâneo. Provavelmente, esse fato se deve à pele clara e ao uso de alimentos fortificados com vitamina D nos escandinavos, enquanto nos países do Mediterrâneo a busca por proteção solar e a pele mais escura favorecem a 
diminuição dos níveis desse metábolito ${ }^{16}$.

A vitamina $D$ é solúvel em gordura e pode ser estocada nas células adiposas. Esse estoque pode ser útil quando a síntese for insuficiente, o que ocorre principalmente durante o inverno ${ }^{15}$. No entanto, ainda não está claro a relação desta vitamina com os adipócitos já que a solubilidade lipídica modifica sua biodisponibilidade e pode contribuir para os baixos níveis detectados em indivíduos com sobrepeso e obesos ${ }^{18}$.

A melhor maneira para aumentar a síntese cutânea de Vitamina D é a exposição curta e regular à luz do solar. Partes do corpo como a cabeça e o pescoço, que recebem luz solar por 20 minutos, produzem a mesma quantidade de vitamina D que todo o corpo exposto por 2 minutos. Ou seja, a exposição de segmentos do corpo pode ser eficiente evitando os riscos de queimadura solar ${ }^{16}$.

Os alimentos suplementados com vitamina D parecem contribuir pouco para manter os níveis séricos adequados desta vitamina, possivelmente pela baixa quantidade acrescentada.

No Brasil o único estudo que quantificou os nutrientes dos diversos alimentos foi realizado na Universidade Estadual de Campinas (UNICAMP). Esse estudo deu origem a Tabela Brasileira de Composição de Alimentos (TACO) e nela não se determinou o valor de vitamina $D^{21}$. Esses valores podem ser encontrados em estudos americanos, sendo a principal referência o USDA (United States Department of Agriculture).

No nosso meio são poucos os estudos que avaliaram os níveis 
séricos de vitamina D na população saudável. Saraiva et al estudando uma população idosa saudável demonstraram elevada incidência de carência desse metabólito. Nesse mesmo estudo avaliou-se o índice de UV (IUV) da cidade de São Paulo, ao longo do ano. Os resultados revelaram que o menor índice ocorreu no mês de junho e no mês seguinte os menores valores de 25(OH)D foram detectados. Contrariamente, em fevereiro a concentração desse metabólito foi mais elevada, decorrente da maior radiação no mês de janeiro ${ }^{20}$.

Unger et al. avaliaram os níveis de 25(OH)D em 603 indivíduos normais na cidade de São Paulo, no final do inverno e destes, 209 foram reavaliados no final do verão. Na primeira amostra, $75 \%$ apresentavam níveis de $25(\mathrm{OH}) \mathrm{D}$ inferiores a $30 \mathrm{ng} / \mathrm{mL}$ e $18 \%$ inferiores a $15 \mathrm{ng} / \mathrm{mL}$. Os autores encontraram uma correlação negativa com a idade e com os níveis de PTH, e positiva com cálcio sérico. Em 40\% dos indivíduos considerados insuficientes, o PTH estava elevado. Após o verão, houve um aumento significativo nos níveis de 25(OH)D, com elevação média de $10,6 \mathrm{ng} / \mathrm{mL}$ e uma diminuição na prevalência de hipovitaminose D. O hiperparatireoidismo também reduziu de $20,6 \%$ no final do inverno para 4,9\% após o verão ${ }^{21}$.

Nos últimos anos diversas publicações de várias partes do mundo têm dedicado especial atenção a esse assunto. Esse interesse se deve a vários fatores, entre eles, ao fato que a deficiência de $25(\mathrm{OH}) \mathrm{D}$ não se associa unicamente ao desenvolvimento de doença óssea como raquitismo nas crianças, osteomalácia, hiperparatireoidismo, osteoporose nos adultos, mas também a outras doenças como, por exemplo, câncer de cólon, 
próstata e de mama, além de hipertensão arterial $^{14,16,17}$.

Estudos epidemiológicos têm demonstrado a importância da monitorização dos níveis de $25(\mathrm{OH}) \mathrm{D}$. Esse metabólito apresenta melhor correlação com certos indicadores clínicos de saúde (por exemplo, densidade mineral óssea) que o metabólito ativo, a 1,25 $(\mathrm{OH})_{2} \mathrm{D}{ }^{17}$.

Trivedi et al. realizaram um estudo prospectivo randomizado e duplo cego, no qual um grupo de indivíduos recebia 10.000 IU de vitamina $D_{3}$ a cada 4 meses durante 5 anos e o outro placebo. No grupo tratado os autores observaram diminuição do número de fraturas ${ }^{22}$. No entanto, uma metaanálise publicada recentemente englobando estudos randomizadoscontrolados, estudo de controle de caso e estudo de corte não mostrou diferença no risco de fratura de quadril entre indivíduos randomizados que receberam tratamento com vitamina $\mathrm{D}$, mesmo em doses elevadas (800Ul/dia ou mais) e placebo. Nos estudos de controle de caso, observaram que os níveis séricos de $25(\mathrm{OH}) \mathrm{D}$ nos indivíduos com fratura de quadril eram inferiores aos controles. Estas evidências indicam que a suplementação com vitamina D não previne o risco de fratura de quadril e que achados observacionais e randomizados diferem entre $\mathrm{si}^{23}$.

Um trabalho baseado em dados do NHAMES III (Third National Health and Nutrition Examination Survey), analisou os níveis de 25(OH)D em 15.088 indivíduos de diversas etnias demonstrando que a redução desse metabólito associava-se a um aumento do risco para doença cardiovascular (DCV). Os autores concluíram também que a 25(OH)D têm uma relação direta com a resistência a insulina, diabetes mellitus e hipertensão arterial. 
O estudo revelou uma associação indireta com obesidade atribuída a baixa exposição ao sol, uma vez que essa população têm um estilo de vida mais sedentário ${ }^{24}$.

Pfeifer et al. estudando mulheres idosas que receberam suplementação com cálcio e vitamina D ou apenas cálcio demonstraram que, no primeiro grupo houve aumento da concentração sérica de 25(OH)D, redução nos níveis de paratormônio, diminuição na pressão arterial sistólica e na freqüência cardíaca ${ }^{25}$.

Em um estudo com pacientes afro-americanos foi encontrado uma associação entre deficiência de $25(\mathrm{OH}) \mathrm{D}$ e gravidade da insuficiência cardíaca congestiva $(\text { ICC })^{26}$.

Em pacientes com doença renal crônica (DRC), o hiperparatireoidismo secundário é uma complicação freqüente e um importante fator de risco para doença cardiovascular ${ }^{27}$. A fisiopatologia do hiperparatiroidismo é complexa, porém existem relatos que demonstram a participação da $25(\mathrm{OH}) \mathrm{D}^{28}$. Assim, níveis reduzidos desse metabólito contribuem para desencadear ou agravar o hiperparatiroidismo e aumentar os riscos para doenças cardiovasculares nessa população ${ }^{28,29}$ de tal forma que no guia de condutas clínicas para osteodistrofia renal ${ }^{30}$ recomenda-se manter os níveis de $25(\mathrm{OH}) \mathrm{D}$ dentro da normalidade, pois essa intervenção diminui a mortalidade desses pacientes.

São poucos os estudos que analisaram níveis de $25(\mathrm{OH}) \mathrm{D}$ nos pacientes transplantados renais. 


\subsection{Transplante renal}

Atualmente no Brasil, cerca de setenta e oito mil pacientes (censo da SBN de 2009) encontram-se em programa de diálise (hemodiálise ou diálise peritoneal) e aproximadamente $50 \%$ deles são elegíveis para transplante renal (TxR) aguardando um órgão ${ }^{30}$. Em 2009, 4259 transplantes renais foram realizados no Brasil $^{31}$. A melhora na qualidade de vida e diminuição da morbidade fazem do TxR a melhor alternativa de tratamento desses pacientes. Entretanto, apesar do sucesso dessa terapia, essa população apresenta elevada incidência de complicações, como doenças cardiovasculares, metabólicas (dislipidemias, diabetes mellitus e doença óssea) e neoplásicas. A persistência da doença óssea após o transplante é freqüente, piora a qualidade de vida e aumenta a morbi-mortalidade desses pacientes $^{32}$.

O TxR bem sucedido geralmente corrige ou melhora os distúrbios do metabolismo mineral e a doença óssea presentes no período dialítico. Porém, muitos pacientes persistem com alterações ósseas, resultado de uma complexa interposição de diferentes fatores. Dentre eles, vale ressaltar a persistência dos distúrbios minerais devido ao funcionamento deficiente do enxerto e a ação de drogas imunossupressoras.

Vários estudos analisaram a doença óssea após o TxR, especialmente no primeiro ano. A maioria deles demonstrou sinais de hiperparatireoidismo ou doença adinâmica, provavelmente refletindo a doença óssea presente na fase da diálise além de alterações ósseas atribuídas à ação dos corticosteróides ${ }^{32,33,34,35}$. 
Os trabalhos que avaliaram a doença óssea após esse período são muito heterogêneos e descrevem um predomínio de baixo remanejamento associado a defeito de mineralização ou doença mista com aumento do número de osteoblastos, osteoclastos e do volume osteóide. Nesses estudos, a osteoporose apresentou uma prevalência de 12 a 56\%. Dentro de uma mesma série de pacientes houve muita variabilidade com relação ao tempo de transplante, e a função do enxerto renal. São vários os fatores que contribuem para o desenvolvimento de doença de baixa remodelação nesses pacientes. Dentre eles a deficiência de vitamina $D$ deve ser lembrada ${ }^{32,33}$

O uso de imunossupressores nos pacientes transplantados aumenta o risco de câncer de pele. Dessa forma os pacientes geralmente são orientados a usar protetor e evitar exposição ao sol. Essa elevada prevalência de deficiência e/ou insuficiência de $25(\mathrm{OH}) \mathrm{D}$ nesses pacientes pode ser conseqüência de ingestão alimentar deficiente, exposição solar inadequadas, ou aumento do catabolismo desse metabólito pelos imunossupressores ${ }^{3,36}$.

Neves et al. realizaram estudo em nosso meio no qual avaliaram o metabolismo mineral e a biopsia óssea de adultos jovens submetidos a TxR. Os pacientes apresentavam funções tireoideana e gonadal normais, função renal preservada, mesmo esquema de imunossupressão mantido desde início do transplante usando dose mínima de corticosteróide. Apesar de critérios rigorosos para inclusão no estudo, nenhum paciente apresentava tecido ósseo normal. Os autores encontraram $30 \%$ de pacientes com 
diminuição do volume ósseo, em $60 \%$ deles a formação óssea estava diminuída, em 33\% a superfície de reabsorção estava elevada e em $46 \%$ observou-se defeito na mineralização óssea. Esses resultados foram semelhantes aos de outros estudos onde os critérios de seleção não foram tão rigorosos, revelando que a doença óssea pós-transplante é freqüente e multifatorial. Entretanto um achado surpreendente foi que $71 \%$ dos pacientes apresentavam insuficiência de $25(\mathrm{OH}) \mathrm{D}^{32}$.

Esses resultados nos motivaram a avaliar qual é a prevalência de deficiência de vitamina $D$ na população de pacientes transplantados renais do Serviço de Transplante Renal do Hospital das Clinicas da Universidade de São Paulo. Além disso, comparamos os níveis de $25(\mathrm{OH}) \mathrm{D}$ desses pacientes com o de indivíduos normais. 


\section{OBJETIVOS}

\section{Principal:}

Avaliar a concentração sérica de 25(OH)D em pacientes transplantados renais visando analisar a prevalência de carência de vitamina D nessa população e os fatores que determinam os níveis desta vitamina, como ingestão alimentar e exposição à luz solar.

\section{Secundário:}

Comparar os resultados da concentração sérica de $25(\mathrm{OH})$ de pacientes transplantados renais com a de indivíduos normais, já que em nosso meio, a carência de vitamina D mostrou-se elevada. 


\section{PACIENTES E MÉTODOS}

\subsection{Casuística}

Em 2008, 752 pacientes com mais de um ano de TxR (12-360 meses), estavam em seguimento no Serviço de Transplante Renal do Hospital das Clínicas da Faculdade de Medicina da Universidade de São Paulo. Desses, 397 eram do sexo masculino (M) e 355 do sexo feminino (F).

O número de participantes do estudo foi determinado através de uma amostra representativa. Para o cálculo do tamanho da amostra consideramos a prevalência de $32,5 \%$ do evento (deficiência de $25(\mathrm{OH}) \mathrm{D}$ ), para o mesmo risco alfa de $5 \%$ e risco Beta de $1 \%$ para um poder do teste de proporção de $99 \%$. Esses índices foram obtidos da curva de poder do teste (figura 1).

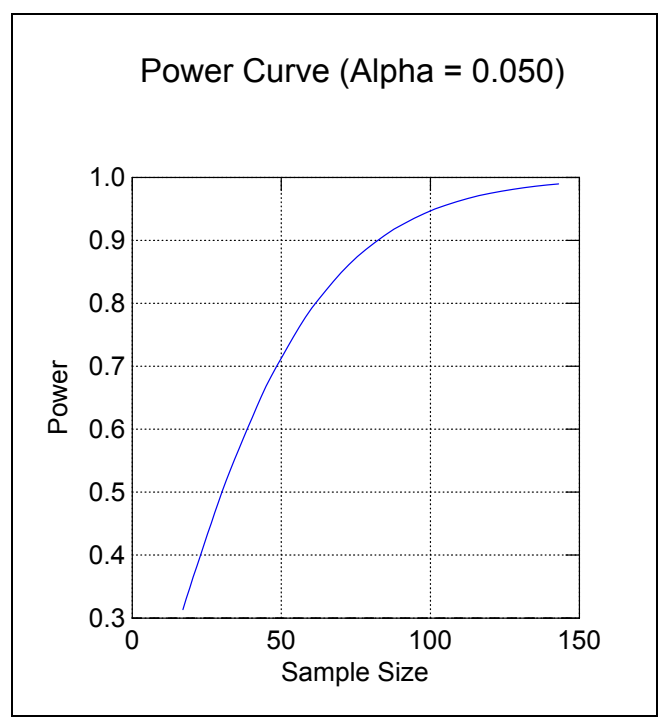

Figura 1. Curva de poder do teste de proporção. 
Considerando a população de 752 pacientes, controlada para raça, sexo, idade, doador vivo/falecido, creatinina e/ou clearance calculado, proteinúria, TGO/TGP/gamaGT, presença de hepatite, drogas imunossupressoras, índice de massa corpórea (IMC) e suplementação vitamínica, o tamanho da amostra foi de 149 pacientes.

Os pacientes selecionados (amostra representativa) foram submetidos a um questionário (anexo A). Analisamos os seguintes parâmetros clínicos: idade, sexo, raça, causa da DRC, tipo de doador, tempo de transplante, esquema imunossupressor, fratura óssea no período do pós TxR (espontânea ou por mínimo trauma).

Foram excluídos pacientes com menos de um ano de transplante, menor de 18 anos de idade e com duplo transplante (rim-fígado; rimpâncreas; rim-coração).

De uma amostra de 603 voluntários (118 M e 485 F) constituída por funcionários do campus da Universidade de São Paulo em acompanhamento ambulatorial no Hospital Universitário da Universidade de São Paulo, além de alunos de Pós-Graduação da Faculdade de Medicina da Universidade de São Paulo estudados por Unger et al., foram selecionados 398 (333 M e 65 F). Foram excluídos os voluntários com diabetes melitus, hipertensão arterial, creatinina sérica superior a 1,2 mg/dL ou aqueles em uso de medicamentos como cálcio, bisfosfonato, suplemento de vitamina $D$ e corticosteróide. Uma amostra de sangue foi colhida no final do inverno de 2006 e nela foram analisados os níveis séricos de cálcio, fósforo, creatinina, albumina, PTH, fosfatase alcalina total, e 25(OH)D. O Índice de Massa 
Corpórea (IMC) foi também calculado. Esses indivíduos constituiram o grupo de normais ${ }^{21}$.

\subsection{Tipo de estudo}

O estudo é do tipo corte transversal.

\subsection{Avaliação laboratorial}

A coleta de sangue foi única e realizada no final do inverno de 2008. Escolhemos o final do inverno pois coincidia com o período de coleta do grupo de normais e pela menor radiação UV. No inverno os níveis de 25(OH)D são menores, o que permitiria detectar maior número de pacientes com deficiência ou insuficiência desta vitamina. Analisamos a creatinina sérica bem como as concentrações de cálcio total $(\mathrm{Ca})$, fósforo $(P)$, paratormônio intacto (PTH), albumina, fosfatase alcalina total (FA), transaminase glutamico oxaloacética (TGO), transaminase glutamico pirúvica (TGP), gamaglutamiltransferase (GGT) e 25(OH)D.

O cálcio sérico total (valores normais: 8,3 a 10,2 $\mathrm{mg} / \mathrm{dL}$ ); fósforo sérico (2,3 a 4,5 mg/dL); albumina (3,5 a 5,0 $\mathrm{g} / \mathrm{dL})$; fosfatase alcalina (40 a 129 U/L) e GGT (até 42 U/L) foram determinados pelo método colorimétrico. A creatinina sérica $(0,7$ a $1,3 \mathrm{mg} / \mathrm{dL})$ foi dosada pelo método picrato alcalino. Foi utilizado o teste UV de acordo com ISCC para a TGO (até 37 U/L) e TGP (até $41 \mathrm{U} / \mathrm{L})$. O PTH intacto (10 a $65 \mathrm{pg} / \mathrm{mL})$ e a 25(OH)D por quimioluminescência. Consideramos insuficiência de 25(OH)D as 
concentrações séricas entre 15 e 30 ng/mL e deficiência as concentrações inferiores a $15 \mathrm{ng} / \mathrm{mL}$.

\subsection{Avaliação dos hábitos de exposição solar}

Os hábitos de exposição solar dos pacientes foram analisados conforme questionário (Anexo B), baseados na freqüência de exposição, horários, tempo, estação do ano, uso de filtro solar, fator de proteção do filtro solar, estação do ano que usa filtro solar, parte do corpo exposta e uso de outros meios físicos de proteção solar.

\subsection{Inquérito dietético}

Os pacientes foram submetidos a um inquérito dietético (Anexo C) de freqüência alimentar, no qual se avaliou a freqüência de consumo dos principais alimentos fonte de vitamina D (peixes gordurosos como salmão, sardinha e atum; e óleo de peixe).

\subsection{Comissão de Ética}

O projeto foi desenvolvido em acordo com as normas éticas da Faculdade de Medicina da Universidade de São Paulo e previamente autorizado pela Comissão de Ética para Análise de Projetos de Pesquisa (CAPPesq) sob nº de protocolo 1035/07 (Anexo D). 


\subsection{Análise estatística}

Os resultados dos parâmetros clínicos e bioquímicos foram expressos em média, desvio padrão, valor mínimo, mediana e valor máximo, enquanto para os dados categóricos foram descritos em freqüência e porcentagem.

Para verificar a relação entre os níveis de $25(\mathrm{OH}) \mathrm{D}$ e outras variáveis categóricas empregamos os testes de Qui-quadrado e, quando necessário, o teste Exato de Fisher.

Utilizamos a transformação de Box e Cox nas variáveis idade, tempo de TxR, albumina, creatinina, PTH, TGO, TGP, GGT e FA para garantir a suposição de normalidade das mesmas.

Mesmo com a transformação de Box e Cox, as variáveis idade, tempo de TxR e TGO não atingiram a normalidade. Como essas variáveis transformadas apresentaram homocedasticidade (pelo teste de Levene) para a comparação dos níveis séricos de $25(\mathrm{OH}) \mathrm{D}$, também foram consideradas com distribuição normal.

Para verificar a relação das variáveis clínicas e bioquímicas com os níveis séricos de 25(OH)D (deficiente, insuficiente ou normal) utilizou-se o modelo ANOVA, e na presença de significância estatística aplicamos o pósteste de Bonferroni.

Constatou-se que os grupos de pacientes transplantados renais e normais são diferentes com relação à variável sexo. Sendo assim, para comparar esses dois grupos com relação às variáveis IMC, P, Ca, Albumina, 
Creatinina, PTH, FA e Vitamina D utilizamos o modelo ANOVA, corrigido por sexo, para cada variável separadamente.

A correlação entre os níveis de $25(\mathrm{OH}) \mathrm{D}$ e os demais parâmetros bioquímicos foi analisada pela correlação de Spearman.

Utilizou-se nesse estudo o nível de significância de 5\% (p-valor $\leq$ 0,05). 


\section{RESULTADOS}

Dos 149 pacientes estudados, 84 eram mulheres e 65 homens, o número daqueles que receberam rins de doadores vivos foi 82 e de falecidos 67. A média de idade foi de $43,8 \pm 12,8$ anos e de tempo de transplante de $7,5 \pm 6,5$ anos. Cento e dois pacientes (68\%) nomearam-se de raça branca.

Quanto à concentração sérica de $25(\mathrm{OH}) \mathrm{D}$ os resultados revelaram que 56 pacientes (37\%) apresentavam deficiência, 62 (42\%) insuficiência e em $31(21 \%)$ a concentração era normal. Dessa forma, a prevalência de deficiência/insuficiência de 25(OH) D na amostra estudada foi de 79,2\%.

A fratura foi referida em $10 \%$ dos pacientes no período pós transplante. O nível médio de $25(\mathrm{OH}) \mathrm{D}$ nos pacientes sem fratura foi semelhante ao dos fraturados $(21,8 \pm 13,2$ vs. $21,9 \pm 8,3)$. Da mesma forma não encontramos diferenças entre as prevalências de deficiência e insuficiência de $25(\mathrm{OH}) \mathrm{D}$ quando comparamos pacientes com e sem fratura.

Os resultados das variáveis clinicas e dos exames bioquímicos realizados nos pacientes transplantados estão descritos na Tabela 1. 
Tabela 1. Resultados das variáveis clínicas e exames bioquímicos dos pacientes transplantados renais

\begin{tabular}{ccc}
\hline & Média \pm DP & Mediana (min - max) \\
\hline Idade (anos) & $43,8 \pm 12,8$ & $44,0(18,0-81,0)$ \\
\hline Tempo de TxR (anos) & $7,5 \pm 6,5$ & $6,0(1,0-36,0)$ \\
\hline IMC (kg/m $)$ & $25,4 \pm 5,3$ & $24,9(16,4-44,0)$ \\
\hline Creatinina (mg/dL) & $1,8 \pm 0,7$ & $1,5(0,6-4,5)$ \\
\hline Clear. de Creatinina (mL/min/1,73) & $63,9 \pm 25,9$ & $64,7(10,7-135,0)$ \\
\hline Albumina (g/dL) & $4,4 \pm 0,4$ & $4,4(3,4-5,5)$ \\
\hline Ca (mg/dL) & $8,9 \pm 0,6$ & $8,9(7,0-10,2)$ \\
\hline P (mg/dL) & $3,0 \pm 0,8$ & $2,9(1,2-5,4)$ \\
\hline PTH (pg/dL) & $80,1 \pm 78,3$ & $53,9(9,5-562,5)$ \\
\hline 25(OH)D (ng/mL) & $22,6 \pm 12,5$ & $21,2(4,2-70,5)$ \\
\hline FA (U/L) & $74,4 \pm 40,1$ & $65,8(29,7-364,5)$ \\
\hline TGO (U/L) & $26,8 \pm 16,6$ & $23,0(6,0-121,0)$ \\
\hline TGP (U/L) & $13,6 \pm 11,6$ & $10,0(3,0-81,0)$ \\
\hline Gama GT (U/L) & $50,7 \pm 79,8$ & $28,0(7,0-704,0)$ \\
\hline
\end{tabular}

DP: desvio padrão; TxR: transplante renal; IMC: Índice de Massa Corpórea; Ca: cálcio; P: fósforo; PTH: hormônio da paratireóide; FA: fosfatase alcalina; TGO: transaminase glutâmico oxaloacética; TGP: transaminase glutâmico pirúvica; Gama GT: gamaglutamiltransferase.

Ressaltamos que quando comparamos pacientes com função hepática alterada, ou seja, aqueles com nível de Gama GT superiores a 50 U/L, com aqueles com função hepática conservada, não encontramos diferenças nos níveis de $25(\mathrm{OH}) \mathrm{D}(21,1 \pm 12,1$ vs. $22,6 \pm 13,4)$.

Na Tabela 2 estão descritas a prevalência das variáveis clinicas estudadas de acordo com classificação dos níveis séricos de 25(OH)D em Deficiente, Insuficiente e Normal. 
Tabela 2. Análise das variáveis clínicas de acordo com a classificação dos níveis séricos de 25(OH)D em Deficiente, Insuficiente e Normal

\begin{tabular}{|c|c|c|c|c|}
\hline & Deficiente & Insuficiente & Normal & $p$-valor \\
\hline $\begin{array}{l}\text { Raça } \\
\text { Branca } \\
\text { Não branca }\end{array}$ & $\begin{array}{l}35(63 \%) \\
21(37 \%)\end{array}$ & $\begin{array}{l}43(69 \%) \\
19(31 \%)\end{array}$ & $\begin{array}{c}24(77 \%) \\
7(23 \%)\end{array}$ & 0,338 \\
\hline $\begin{array}{l}\text { Sexo } \\
\text { Feminino } \\
\text { Masculino }\end{array}$ & $\begin{array}{l}30(54 \%) \\
26(46 \%)\end{array}$ & $\begin{array}{l}35(56 \%) \\
27(44 \%)\end{array}$ & $\begin{array}{l}19(61 \%) \\
12(39 \%)\end{array}$ & 0,789 \\
\hline $\begin{array}{l}\text { IMC }\left(\mathbf{k g} / \mathbf{m}^{\mathbf{2}}\right) \\
\text { Não obeso } \\
\text { Obeso }\end{array}$ & $\begin{array}{l}29(52 \%) \\
27(48 \%)\end{array}$ & $\begin{array}{l}34(55 \%) \\
28(45 \%)\end{array}$ & $\begin{array}{l}16(52 \%) \\
15(48 \%)\end{array}$ & 0,653 \\
\hline $\begin{array}{l}\text { Doador } \\
\text { Vivo } \\
\text { Falecido } \\
\end{array}$ & $\begin{array}{l}28(50 \%) \\
28(50 \%) \\
\end{array}$ & $\begin{array}{l}31(50 \%) \\
31(50 \%) \\
\end{array}$ & $\begin{array}{c}23(74 \%) \\
8(26 \%) \\
\end{array}$ & 0,057 \\
\hline $\begin{array}{l}\text { Fratura pós TxR } \\
\text { Não } \\
\text { Sim }\end{array}$ & $\begin{array}{c}52(93 \%) \\
4(7 \%)\end{array}$ & $\begin{array}{c}53(85 \%) \\
9(15 \%)\end{array}$ & $\begin{array}{c}29(93 \%) \\
2(7 \%)\end{array}$ & 0,299 \\
\hline $\begin{array}{l}\text { Imunossupressores } \\
\text { CSA ou FK } \\
\text { Não uso de CSA e FK }\end{array}$ & $\begin{array}{l}44(79 \%) \\
12(21 \%)\end{array}$ & $\begin{array}{l}43(69 \%) \\
19(31 \%)\end{array}$ & $\begin{array}{l}20(64 \%) \\
11(36 \%)\end{array}$ & 0,324 \\
\hline
\end{tabular}

IMC: Índice de Massa Corpórea; TxR: transplante renal; CSA: ciclosporina; FK: tacrolimus.

Somente o tipo de doador apresentou diferenças que ficaram próximas da significância, ou seja, $26 \%$ dos pacientes que receberam rim de doador falecido apresentaram níveis normais de $25(\mathrm{OH}) \mathrm{D}$ contra $50 \%$ de insuficientes e deficientes.

Tabela 3. Análise das variáveis de exposição ao sol de acordo com a classificação dos níveis séricos de $25(\mathrm{OH})$ D em Deficiente, Insuficiente e Normal

\begin{tabular}{lcccc}
\hline & Deficiente & Insuficiente & Normal & p-valor \\
\hline Freqüência de exposição ao sol & $2(4 \%)$ & $13(20 \%)$ & $19(61 \%)$ & $<0,0001$ \\
3 ou mais vezes por semana & $51(96 \%)$ & $52(80 \%)$ & $12(39 \%)$ & \\
$\quad$ menos de 3 vezes por semana & $16(29 \%)$ & $14(23 \%)$ & $13(42 \%)$ & 0,207 \\
\hline Uso de filtro solar & $40(71 \%)$ & $47(77 \%)$ & $18(58 \%)$ & \\
$\quad$ Sim & & & & \\
Não & & &
\end{tabular}


A freqüência de exposição ao sol também influenciou a concentração sérica de $25(\mathrm{OH}) \mathrm{D}$. Observamos diferença significativa entre os níveis de 25(OH)D para quem se expõem ao sol mais de 3 vezes por semana comparados aos que raramente se expõem. O uso de filtro solar não influenciou a concentração sérica dessa vitamina.

Tabela 4. Análise do consumo de alimentos fonte de vitamina $D$ de acordo com a classificação dos níveis séricos de 25(OH)D em Deficiente, Insuficiente e Normal

\begin{tabular}{lcccc}
\hline & Deficiente & Insuficiente & Normal & p-valor \\
\hline Alimento fonte & & & & \\
Frequente & $5(9 \%)$ & $6(10 \%)$ & $7(23 \%)$ & \multirow{0}{*}{$\mathbf{1 4}$} \\
Raramente & $48(91 \%)$ & $57(90 \%)$ & $24(77 \%)$ & \\
\hline
\end{tabular}

Não encontramos diferença significativa entre os níveis de $25(\mathrm{OH}) \mathrm{D}$ e o consumo de alimentos fontes.

Nas tabelas 5 e 6 estão descritas as comparações dos parâmetros clínicos e bioquímicos, respectivamente, quando os pacientes foram classificados de acordo com os níveis séricos de 25(OH)D em deficientes, insuficientes e normais.

Tabela 5. Comparação dos parâmetros clínicos estudados de acordo com a classificação dos pacientes quanto aos níveis séricos de Vitamina D

\begin{tabular}{|c|c|c|c|c|}
\hline & $\begin{array}{c}\text { Deficiente } \\
(n=56)\end{array}$ & $\begin{array}{l}\text { Insuficiente } \\
(\mathrm{n}=62)\end{array}$ & $\begin{array}{c}\text { Normal } \\
(\mathrm{n}=31)\end{array}$ & p-valor \\
\hline \multicolumn{5}{|l|}{ Idade (anos) } \\
\hline Média \pm DP & $42,8 \pm 13,0$ & $45,2 \pm 12,3$ & $42,5 \pm 13,7$ & 0,491 \\
\hline Mediana (min - max) & $43,0(22-81)$ & $45,5(25-68)$ & $42,0(18-64)$ & \\
\hline \multicolumn{5}{|c|}{ Tempo de TxR (anos) } \\
\hline Média \pm DP & $7,0 \pm 4,7$ & $7,6 \pm 7,5$ & $8,2 \pm 7,4$ & 0,696 \\
\hline Mediana (min - max) & $6,5(1-19)$ & $5,0(1-35)$ & $6,0(1-36)$ & \\
\hline \multicolumn{5}{|l|}{ IMC $\left(\mathrm{kg} / \mathrm{m}^{2}\right)$} \\
\hline Média \pm DP & $26,4 \pm 6,2$ & $24,6 \pm 4,2$ & $25,1 \pm 5,2$ & 0,171 \\
\hline Mediana (min - max) & $24,9(17,2-$ & $24,9(16,4-39,1)$ & $24,9(18,9-$ & \\
\hline
\end{tabular}


Tabela 6. Comparação dos parâmetros bioquímicos de acordo com a classificação dos pacientes quanto aos níveis séricos de Vitamina D

\begin{tabular}{|c|c|c|c|c|}
\hline & Deficiente & Insuficiente & Normal & $p$-valor \\
\hline Creatinina (mg/dL) & $(n=53)$ & $(n=60)$ & $(n=31)$ & \\
\hline Média \pm DP & $2,0 \pm 0,9$ & $1,7 \pm 0,7$ & $1,5 \pm 0,5$ & 0,013 \\
\hline Mediana (min - max) & $1,7(1,0-4,5)$ & $1,5(0,6-4,1)$ & $1,3(1,0-2,7)$ & \\
\hline Cl. Creatinina $(\mathrm{mL} / \mathrm{min} / 1,73)$ & $(n=56)$ & $(n=62)$ & $(n=31)$ & \\
\hline Média \pm DP & $63,1 \pm 30,1$ & $61,7 \pm 23,2$ & $69,5 \pm 23,1$ & 0,388 \\
\hline Mediana (min - max) & $59,4(10,7-135,0)$ & $65,4(13,6-109,2)$ & $70,0(29,4-134,9)$ & \\
\hline Albumina (g/dL) & $(n=52)$ & $(n=60)$ & $(n=31)$ & \\
\hline Média \pm DP & $4,4 \pm 0,5$ & $4,4 \pm 0,3$ & $4,4 \pm 0,4$ & 0,660 \\
\hline Mediana (min - max) & $4,4(3,4-5,3)$ & $4,4(3,8-5,2)$ & $4,5(3,4-5,5)$ & \\
\hline$\overline{C a}(\mathrm{mg} / \mathrm{dL})$ & $(n=51)$ & $(n=59)$ & $(n=31)$ & \\
\hline Média \pm DP & $8,9 \pm 0,7$ & $8,9 \pm 0,5$ & $8,9 \pm 0,5$ & 0,997 \\
\hline Mediana (min - max) & $9,0(7,0-10,2)$ & $8,9(7,8-9,9)$ & $8,8(7,8-10,1)$ & \\
\hline$P$ (mg/dL) & $(n=55)$ & $(n=61)$ & $(n=31)$ & \\
\hline Média \pm DP & $3,0 \pm 0,8$ & $3,0 \pm 0,8$ & $2,7 \pm 0,6$ & 0,154 \\
\hline Mediana (min - max) & $2,9(1,2-5,4)$ & $2,9(1,3-5,3)$ & $2,7(1,2-3,8)$ & \\
\hline PTH (pg/dL) & $(n=55)$ & $(n=61)$ & $(n=31)$ & \\
\hline Média \pm DP & $104,7 \pm 104,6$ & $72,5 \pm 58,6$ & $51,6 \pm 37,0$ & 0,011 \\
\hline Mediana (min - max) & $68,6(18,2-562,5)$ & $53,2(9,5-277,0)$ & $44,1(13,3-229,8)$ & \\
\hline$\overline{F A(U / L)}$ & $(n=53)$ & $(n=60)$ & $(n=31)$ & \\
\hline Média \pm DP & $82,8 \pm 54,5$ & $71,6 \pm 30,3$ & $65,8 \pm 23,4$ & 0,441 \\
\hline Mediana ( $\min -\max )$ & $69,6(29,7-364,5)$ & $64,8(34,2-191,0)$ & $65,6(34,5-166,4)$ & \\
\hline PCR (mg/dL) & $(n=55)$ & $(n=61)$ & $(n=31)$ & \\
\hline Média \pm DP & $0,6 \pm 1,4$ & $0,7 \pm 1,9$ & $0,4 \pm 0,5$ & 0,812 \\
\hline Mediana (min - max) & $0,1(0,0-8,9)$ & $0,2(0,0-13,6)$ & $0,1(0,0-1,6)$ & \\
\hline$\overline{\text { TGO (U/L) }}$ & $(n=52)$ & $(n=60)$ & $(n=31)$ & \\
\hline Média \pm DP & $27,9 \pm 22,8$ & $27,8 \pm 11,7$ & $23,5 \pm 12,2$ & 0,445 \\
\hline Mediana (min - max) & $21(6-121)$ & $25(9-64)$ & $19(13-67)$ & \\
\hline$\overline{\text { TGP (U/L) }}$ & $(n=53)$ & $(n=60)$ & $(n=31)$ & \\
\hline Média \pm DP & $14,2 \pm 13,2$ & $13,3 \pm 8,5$ & $13,2 \pm 14,2$ & 0,387 \\
\hline Mediana (min - max) & $10,0(4-81)$ & $10,5(3-44)$ & $9,0(4-77)$ & \\
\hline$\overline{\text { Gama GT (U/L) }}$ & $(n=51)$ & $(n=58)$ & $(n=31)$ & \\
\hline Média \pm DP & $67,5 \pm 116,9$ & $44,1 \pm 50,1$ & $35,6 \pm 37,2$ & 0,324 \\
\hline Mediana (min - max) & $31(7-704,0)$ & $28(10-334)$ & $22(12-206)$ & \\
\hline
\end{tabular}

Esses resultados revelaram que apenas os níveis séricos de creatinina e PTH são significativamente distintos quando os pacientes foram classificados como deficientes, insuficientes e normais em 25(OH)D. 
Aplicando-se o teste de Bonferroni para comparações múltiplas nas variáveis significativas (creatinina e PTH) observamos diferenças nos níveis de creatinina e PTH entre os pacientes deficientes e normais em Vitamina D.

Tabela 7. Comparações múltiplas entre as categorias de pacientes classificados em Deficientes, Insuficientes e Normais

\begin{tabular}{ll}
\hline & $\boldsymbol{p}$-valor \\
\hline Creatinina & 0,080 \\
Deficiente vs. Insuficiente & $\mathbf{0 , 0 1 9}$ \\
Deficiente vs. Normal & 1,000 \\
Insuficiente vs. Normal & \\
\hline PTH & 0,196 \\
Deficiente vs. Insuficiente & $\mathbf{0 , 0 1 0}$ \\
Deficiente vs. Normal & 0,430 \\
Insuficiente vs. Normal &
\end{tabular}

$\mathrm{Na}$ tabela 8 estão descritos os resultados da comparação dos parâmetros clínicos entre os pacientes transplantados renais e os indivíduos normais.

Tabela 8. Comparação entre os pacientes transplantados renais e indivíduos normais quanto a distribuição pela Faixa Etária, Sexo e Raça

\begin{tabular}{lccc}
\hline & Normais & Transplantados & p-valor \\
\hline Faixa etária & $68(17 \%)$ & $29(19 \%)$ & \\
18 a 30 anos & $210(53 \%)$ & $71(48 \%)$ & \\
31 a 50 anos & $97(25 \%)$ & $46(31 \%)$ & 0,078 \\
51 a 65 anos & $20(5 \%)$ & $3(2 \%)$ & \\
$\quad$ Mais de 65 anos & $333(84 \%)$ & $84(56 \%)$ & $<0,001$ \\
\hline Sexo & $65(16 \%)$ & $65(44 \%)$ & \\
$\quad$ Feminino & $269(68 \%)$ & $102(68 \%)$ & 0,151 \\
$\quad$ Masculino & $116(29 \%)$ & $47(32 \%)$ & \\
\hline Raça & & & \\
$\quad$ Branca & &
\end{tabular}


Analisando os resultados, observamos que os pacientes transplantados e os indivíduos saudáveis diferiam quanto a distribuição pelo sexo. Quando comparamos a idade dos pacientes transplantados e normais $(43,8 \pm 12,8$ vs. $43,9 \pm 12,6)$ não encontramos diferenças entre os grupos.

Os resultados expressos na Tabela 9 revelaram uma diferença significativa entre os transplantados e os indivíduos normais quanto aos níveis de $\mathrm{Ca}, \mathrm{P}$, Creatinina, Albumina e PTH.

Tabela 9. Comparação dos parâmetros antropométricos e bioquímicos entre indivíduos normais e transplantados

\begin{tabular}{|c|c|c|c|}
\hline & Normais & Transplantados & ${ }^{*} p$-valor \\
\hline $\mathrm{IMC}\left(\mathrm{kg} / \mathrm{m}^{2}\right)$ & $(n=348)$ & $(n=149)$ & \\
\hline Média \pm DP & $25,9 \pm 4,9$ & $25,4 \pm 5,3$ & 0,118 \\
\hline Mediana (min - max) & $25,2(16,8-56,3)$ & $24,9(16,4-44,0)$ & \\
\hline$P(\mathrm{mg} / \mathrm{dL})$ & $(n=383)$ & $(n=147)$ & \\
\hline Média \pm DP & $3,8 \pm 0,7$ & $3,0 \pm 0,8$ & $<0,001$ \\
\hline Mediana (min - max) & $3,8(1,8-7,6)$ & $2,9(1,2-5,4)$ & \\
\hline $\mathrm{Ca}$ (mg/dL) & $(n=382)$ & $(n=142)$ & \\
\hline Média \pm DP & $9,6 \pm 0,5$ & $8,9 \pm 0,6$ & $<0,001$ \\
\hline Mediana (min - max) & $9,6(6,7-10,8)$ & $8,9(7,0-10,2)$ & \\
\hline Albumina (g/dL) & $(n=384)$ & $(n=144)$ & \\
\hline Média $\pm \mathrm{DP}$ & $4,5 \pm 0,3$ & $4,4 \pm 0,4$ & $<0,001$ \\
\hline Mediana (min - max) & $4,5(3,3-5,4)$ & $4,4(3,4-5,5)$ & \\
\hline Creatinina (mg/dL) & $(n=382)$ & $(n=145)$ & \\
\hline Média \pm DP & $0,8 \pm 0,1$ & $1,8 \pm 0,7$ & $<0,001$ \\
\hline Mediana (min - max) & $0,8(0,4-1,2)$ & $1,5(0,6-4,5)$ & \\
\hline PTH (pg/dL) & $(n=352)$ & $(n=148)$ & \\
\hline Média \pm DP & $64,9 \pm 24,8$ & $80,1 \pm 78,3$ & $<0,001$ \\
\hline Mediana (min - max) & $60,5(5,0-144,0)$ & $53,9(9,5-562,5)$ & \\
\hline FA (U/L) & $(n=381)$ & $(n=145)$ & \\
\hline Média \pm DP & $70,9 \pm 26,1$ & $74,4 \pm 40,1$ & 0,306 \\
\hline Mediana (min - max) & $69,0(24,0-369,0)$ & $65,8(29,7-364,5)$ & \\
\hline 25(OH)D (ng/dL) & $(n=398)$ & $(n=149)$ & \\
\hline Média \pm DP & $23,8 \pm 10,4$ & $21,8 \pm 12,8$ & 0,056 \\
\hline Mediana (min - max) & $21,6(6,0-64,3)$ & $20,7(4,0-70,5)$ & \\
\hline
\end{tabular}

$\mathrm{Na}$ Tabela 10 estão descritos os resultados da distribuição de 
pacientes e indivíduos normais segundo os níveis de $25(\mathrm{OH}) \mathrm{D}$ (deficiente, insuficiente e normal). por grupo de pacientes transplantados renais e indivíduos normais. O grupo de transplantados apresenta maior percentual de pacientes com deficiência de 25(OH)D.

Tabela 10. Distribuição de pacientes transplantados renais e indivíduos normais segundo os níveis de $25(\mathrm{OH}) \mathrm{D}$ classificados por Deficientes, Insuficientes e Normais

\begin{tabular}{cccc}
\hline Nível de 25(OH)D & $\begin{array}{c}\text { Normais } \\
(\mathbf{n = 3 9 8})\end{array}$ & $\begin{array}{c}\text { Transplantados } \\
(\mathbf{n = 1 4 9 )}\end{array}$ & p-valor \\
\hline Deficiente & $90(23 \%)$ & $56(37 \%)$ & \\
Insuficiente & $209(52 \%)$ & $62(42 \%)$ & $\mathbf{0 , 0 0 1}$ \\
Normal & $99(25 \%)$ & $31(21 \%)$ & \\
\hline
\end{tabular}

Analisamos as correlações entre os níveis séricos de $25(\mathrm{OH}) \mathrm{D}$ e os parâmetros bioquímicos e encontramos unicamente uma correlação inversa com os níveis de PTH sérico $(r=-0,24 ; p<0,03)$. 


\section{DISCUSSÃO}

Este estudo revelou que $80 \%$ dos pacientes transplantados renais da Unidade de Transplante Renal do Hospital das Clinicas da Universidade de São Paulo apresentavam insuficiência ou deficiência de 25(OH)D após o inverno. Esses resultados são semelhantes aos de outros estudos realizados em diferentes partes do mundo, especialmente no hemisfério norte, e em diferentes períodos do ano. Neles a prevalência de insuficiência/deficiência de $25(\mathrm{OH}) \mathrm{D}$ variou de 76 a $97 \% .^{37,38,39,40,41} \mathrm{O}$ fato do Brasil apresentar elevados níveis de insolação, mesmo na latitude onde realizamos o estudo, não preveniu a deficiência de vitamina $D$ nesses pacientes.

Nos últimos anos a associação entre deficiência dessa vitamina com doenças ósseas, doenças cardiovasculares, cânceres, entre outras patologias fez com que muitos profissionais se dessem conta da importância de sua dosagem bem como reposição. Muito se discute sobre qual é a melhor técnica de dosagem e todas tem limitações, faltando uma padronização internacional para melhor diagnosticar e compreender a deficiência de vitamina $D^{9}$.

Recentemente, Snellman et al. compararam as dosagens de $25(\mathrm{OH}) \mathrm{D}$ empregando a técnica HPLC, considerada o "gold standard", com kits comercialmente disponíveis. Além da grande variabilidade dos resultados os autores demonstraram valores mais baixos com a técnica de quimiluminescência, que foi a que utilizamos. Dessa forma nossos 
resultados podem estar subestimados ${ }^{42}$.

Optamos por avaliar nossos pacientes após o inverno período do ano onde as concentrações de vitamina D estão mais reduzidas, visando diagnosticar um maior numero de pacientes com deficiência/insuficiência. Stavroulopoulos et al. analisaram pacientes transplantados no verão e inverno confirmando níveis mais reduzidos dessa vitamina no inverno ${ }^{41}$.

Encontramos uma associação próxima da significância entre o tipo de doador e a prevalência de deficiência/ insuficiência de 25(OH)D quando classificamos em rins de doador vivo e falecido. Esse resultado é relevante na medida em que $75 \%$ dos pacientes com níveis normais de $25(\mathrm{OH}) \mathrm{D}$ receberam rim de doador vivo. Vale lembrar que a creatinina sérica dos dois

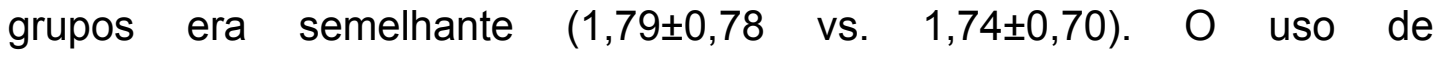
imunossupressores não influenciou os níveis de $25(\mathrm{OH}) \mathrm{D}$ mesmo quando analisamos isoladamente os diferentes esquemas terapêuticos. Apesar da maioria dos estudos afirmar que essas drogas diminuem os níveis séricos da 25(OH)D, somente a comparação de pacientes com esquemas distintos e sem modificações, durante a maior parte do tempo poderia realmente avaliar a participação dessas drogas na síntese de vitamina $D$.

A freqüência de exposição à luz solar foi um determinante dos níveis de vitamina $D$ nos nossos pacientes. A luz solar é considerada a principal fonte de vitamina $D$ e pacientes transplantados se protegem da exposição para evitar câncer de pele. ${ }^{43,44}$ No entanto, dados epidemiológicos apontam para um papel positivo da exposição ao sol em detrimento da mortalidade por esse tipo de câncer ${ }^{43}$. Dessa forma, orientações no sentido de permitir a 
exposição por curto período de tempo poderiam ser benéficas, e provavelmente não aumentariam o risco de câncer de pele.

Diferentemente de outros estudos como de Sadlier e Magee em que a deficiência de $25(\mathrm{OH}) \mathrm{D}$ foi maior em negros comparados com não negros $(40,7 \%$ vs. $24,7 \%)$, não encontramos diferença quanto à raça ${ }^{40}$. Vale ressaltar que não classificamos detalhadamente o tipo de pele dos pacientes empregando, por exemplo, a classificação de Fitzpatrick ${ }^{45}$, no entanto, a grande miscigenação da população brasileira, e a dificuldade de nomeação da própria raça devem ter interferido nos resultados.

Não encontramos associação com o uso de filtro solar e níveis de 25(OH)D. Isto pode ser atribuído ao uso inconstante do filtro, já que existe a recomendação, mas nem sempre é seguida corretamente.

Também não observamos diferença quanto à ingestão de alimentos fontes. Realizamos inquérito alimentar baseando-se somente na freqüência de ingestão de alimentos fonte e não na quantidade consumida, uma vez que são poucos os alimentos ricos nessa vitamina. Entre eles consideramos: o salmão (600Ul Vit D/100g), a sardinha (300Ul Vit D/100g), o atum (230UI Vit D/100g) ou se o paciente fazia uso de óleo de peixe (200Ul Vit D/50g). Esse resultado merece uma consideração, pois de uma maneira geral, os alimentos fonte que avaliamos são pouco ingeridos pela população brasileira, seja pelo próprio habito alimentar ou pelo custo elevado. Mesmo a sardinha, que é mais acessível, não é consumida pela maior parte da nossa população. 
Quanto aos alimentos fortificados, eles praticamente não foram levados em consideração nesse estudo uma vez que no Brasil são poucos os alimentos fortificados (margarinas, manteigas, leites) e neles a quantidade de vitamina $D$ acrescentada é irrisória.

A falta de tabelas brasileiras de composição nutricional com o teor de vitamina $\mathrm{D}$ dos alimentos dificulta a avaliação da quantidade real ingerida.

Na Dinamarca, Heaf et al. detectaram baixa ingestão de vitamina $D$ $(3,02 \pm 2,87 \mu \mathrm{g}$ versus $5 \mu \mathrm{g}=200 \mathrm{UI}$ recomendado $)$ após avaliar os hábitos dietéticos de pacientes transplantados renais através de inquérito alimentar de 3 dias $^{46}$. Em Tromso, ao norte da Noruega, a população tem uma elevada ingestão de vitamina D na "estação do bacalhau" que acontece durante o inverno. Apesar disto, os níveis séricos de $25(\mathrm{OH}) \mathrm{D}$ nesta população é $30 \%$ maior no verão. Isto reforça a importância do sol como fonte de vitamina D mesmo nas altas latitudes ${ }^{47}$. Recentes investigações sugerem que não é possível manter níveis adequados de $25(\mathrm{OH})$ com a ingestão diária de vitamina D recomendada pela RDA (Recommended Dietary Allowance) que é de 200 UI para adultos jovens ${ }^{48}$.

O estado nutricional dos pacientes não teve relação com os níveis séricos de 25(OH)D. Encontramos elevada prevalência de pacientes obesos, porém semelhante à de outros estudos $(48 \%)^{49,50,51}$. Vale lembrar que na obesidade a biodisponibilidade da $25(\mathrm{OH}) \mathrm{D}$, pode ser influenciada pelo seu armazenamento nos adipócitos.

Encontramos uma correlação inversa entre os níveis de PTH e 
25(OH)D o que também foi detectado em outros estudos. Stavroulopoulos et al. observaram essa correlação apenas no inverno e no grupo de pacientes com transplante tardio ${ }^{41}$. Outros dois estudos (Boudville e Sadlier) observaram deficiência em $76 \%$ e $88 \%$ dos pacientes respectivamente, e os níveis séricos de PTH também foram influenciados pelos de $25(\mathrm{OH}) \mathrm{D} .^{38,40}$. Estudo de Giannini et al. revelou que pacientes com níveis de 25(OH)D inferiores a 30nmol/L cursavam com níveis mais elevados de $\mathrm{PTH}$ quando comparados aos que tinham níveis superiores a $30 \mathrm{nmol} / \mathrm{L}^{52}$. Somente o estudo de Sezer et al. não encontrou correlação entre os níveis de 25(OH)D e os de $\mathrm{PTH}^{53}$.

Unger et al. demonstraram que indivíduos normais, no inverno desenvolvem hiperparatireoidismo secundário à deficiência de $25(\mathrm{OH}) \mathrm{D}$ que desaparece no verão. Dessa forma a elevação do PTH poderia ser uma compensação fisiológica a queda de produção de $25(\mathrm{OH}) \mathrm{D}$ que ocorre no inverno. Nos pacientes transplantados os estudos foram realizados em diferentes épocas do ano o que impede que se saiba se esses pacientes seguem o que se observa na população normal ${ }^{21}$. No entanto, vale ressaltar que os pacientes transplantados apresentam vários fatores que contribuem para a persistência do hiperparatireoidismo secundário e a deficiência de 25(OH)D deve ser lembrada. A deficiência também pode influenciar o defeito de mineralização observado em muitos pacientes, contribuindo para manter ou até agravar a doença óssea pós-transplante.

No nosso estudo os pacientes com deficiência de 25(OH)D apresentaram níveis mais elevados de creatinina sérica. Sezer et al ${ }^{53}$ 
seguiram pacientes transplantados durante um ano e encontraram uma associação entre baixos níveis de $25(\mathrm{OH}) \mathrm{D}$ e perda de função renal.

Embora a prevalência de insuficiência de 25(OH)D tenha sido semelhante a observada nos indivíduos normais, os pacientes transplantados apresentaram maior porcentagem de deficientes (37\% vs. $23 \%$, com $p=0,001)$. No estudo de Querings et al., os níveis séricos de 25(OH)D nos pacientes transplantados renais foram significativamente mais baixos quando comparados com o grupo controle, no final do inverno ${ }^{54}$.

As comparações dos níveis séricos de cálcio, fósforo, albumina, creatinina e PTH entre a população normal e os pacientes transplantados mostraram diferenças significativas. Isso provavelmente se deve ao tipo de amostra que analisamos da qual constava pacientes com diferentes níveis de função renal.

Vários autores tem proposto o tratamento da deficiência/insuficiência de 25(OH)D. Couberbaisse et al. trataram pacientes com $100.000 \mathrm{UI}$ de colecalciferol a cada 2 semanas por 2 meses. Esta quantidade foi suficiente para elevar o nível sérico de $25(\mathrm{OH}) \mathrm{D}$ acima de $30 \mathrm{ng} / \mathrm{mL}$ e reduzir o nível de PTH sem causar hipercalcemia e aumento na excreção de cálcio urinário ${ }^{55}$. 


\section{CONCLUSÕES}

Através deste estudo pôde-se concluir que é importante fazer o diagnóstico de insuficiência e deficiência de $25(\mathrm{OH}) \mathrm{D}$ e de preferência no período imediato do transplante, já que sua prevalência é elevada. Observamos que a frequência de exposição solar relacionou-se positivamente com os níveis de $25(\mathrm{OH}) \mathrm{D}$, mas o consumo de alimentos fonte de vitamina $D$ não, provavelmente pelo número reduzido de pacientes que incluem esses alimentos na dieta. No entanto, como este é um estudo de corte, seria necessário outros a longo prazo que melhor avaliassem tanto a ingestão de vitamina $\mathrm{D}$ como a quantidade de radiação solar a qual os pacientes transplantados renais são submetidos. E assim, incluir orientação dietética, a fim de introduzir novos hábitos alimentares na dieta e consequentemente quantidades suficientes de vitamina $D$ para suprir as necessidades, como também exposição solar com parcimônia, ou seja, curta e regular para não causar danos à pele. Desta maneira, é possível melhorar a doença óssea. A suplementação com vitamina $D$ é também uma maneira fácil e segura de assegurar níveis adequados dessa vitamina. 


\section{ANEXOS}

\section{Anexo A - Questionário aplicado aos pacientes}

PROTOCOLO - Deficiência de 25(OH)D em pacientes TXR

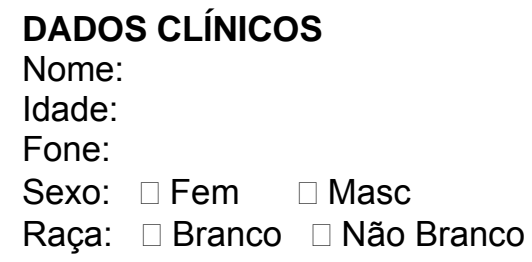

Biópsia hepática: $\square \operatorname{sim} \quad \square$ não

\section{ANTECEDENTES DO TRANSPLANTE}

Data do Tx (mm/aa):

Doador: $\square$ vivo relac. $\square$ vivo não-relac. $\square$ cadáver

Esquema imunossupressor:

$\square$ Pred $\square$ AZA $\square$ CSA $\square$ FK $\square$ Rapa $\square$ MMF

Queixas clínicas (relacionada à doença óssea):

Usa anticonvulsivante: $\square \operatorname{sim} \quad \square$ não

Fratura: $\square \operatorname{sim} \square$ não

$\mathrm{N}^{\circ}$ :

Onde:

Quando (meses após TX):

Uso de vitamina D:

Uso de outras suplementações vitamínicas:

Peso:

IMC:

Alt: 


\section{Anexo B - Hábitos de exposição solar}

\section{PROTOCOLO - Avaliação dos hábitos de exposição solar}

DADOS CLÍNICOS

Nome:

Idade:

Fone:

Sexo: $\square$ Fem $\square$ Masc

Raça: $\square$ Branco $\square$ Negro $\square$ Pardo $\square$ Amarelo

\section{HÁBITO DE EXPOSIÇÃO SOLAR}

Frequência da exposição solar:

$\square 3$ a 7 x/semana $\square 1$ a 2 x/semana $\square$ primavera/verão $\square$ nunca

Partes do corpo: $\square$ todo $\square$ mms superiores, inferiores e rosto $\square$ rosto e mãos Tempo de exposição:

Horário:

Uso de filtro solar $\square$ não $\square$ sim Fator de proteção:

Indicação dermatológica: $\square$ não $\square$ sim

Estação do ano que usa o filtro solar:

Uso de roupas fechadas $\square \operatorname{sim} \square$ não

Uso de outros meios físicos de proteção solar:

\section{Data consulta:}

RG:

Data nasc: 


\section{Anexo C - Freqüência Alimentar}

Nome:

Data :

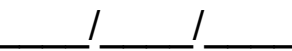

\begin{tabular}{|l|l|}
\hline Alimento & Frequência \\
\hline Óleo de peixe & \\
\hline Peixes gordurosos & \\
(salmão, sardinha, atum) & \\
\hline & \\
\hline
\end{tabular}




\section{Anexo D - Aprovação pela Comissão de Ética}

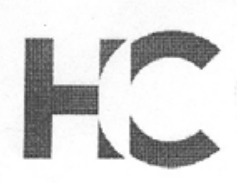

\section{APROVAÇÃO}

A Comissão de Ética para Análise de Projetos de Pesquisa CAPPesq da Diretoria Clínica do Hospital das Clínicas e da Faculdade de Medicina da Universidade de São Paulo, em sessão de 07/12/2007, APROVOU o Protocolo de Pesquisa n 1035/07, intitulado: "DEFICIÊNCIA DE VITAMINA D EM PACIENTES TRANSPLANTADOS RENAIS: ANÁLISE DA PREVALÊNCIA" apresentado pelo Departamento de Clínica Médica, inclusive o Termo de Consentimento Livre e Esclarecido.

Cabe ao pesquisador elaborar e apresentar à CAPPesq, os relatórios parciais e final sobre a pesquisa (Resolução do Conselho Nacional de Saúde n 196, de 10/10/1996, inciso IX.2, letra "c").

Pesquisador (a) Responsável: Vanda Jorgetti

Pesquisador (a) Executante: Cristiane Flores Vilarta

CAPPesq, 07 de Dezembro de 2007

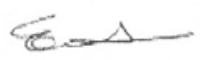

Prof. Dr. Eduardo Massad Presidente da Comissão de Ética para Análise de Projetos de Pesquisa

Comissăo de Ética para Análise de Projetos de Pesquisa do HCFMUSP e da FMUSP Diretoria Clinica do Hospital das Clinicas da Faculdade de Medicina da Universidade de São Paulo Rua Ovídio Pires de Campos, 255. $5^{\circ}$ andar - CEP 05403 010 - São Paulo - SP Fone: 01130696442 Fax: 01130696492 e-mail: cappesq@hcnet usp.br / 


\section{REFERÊNCIAS}

1. Holick MF, Chen TC, Lu Z, Sauter E. Vitamin D and skin physiology: a dlightful story. J Bone Miner Res, 2007;22(S2):V28-V33.

2. Holick MF, Garabedian M. Chapter 17: Vitamin D: Photobioly, Metabolism, Mechanism of Action, and Clinical Application. In: Primer on the Metabolic Bone Diseases and Disorders of Mineral Metabolism. $6^{\circ}$ ed, 2006; 106-14.

3. Holick MF. Resurrection of vitamin D deficiency and rickets. J Clin Invest, 2006;116(8):2062-72.

4. Holick MF. Vitamin D: a D-lightful health perspective. Nutrition Review,. 2008;66(2):S182-S194.

5. Sergesten $U$. 25-hydroxyvitamin $D_{3} 1$-alfahydroxilase expression in normal and phatologica parathyroid glands. J Clin Endocrinol Metabol, 2002; 87(6):2967-72

6. Ritter CS, Armbrecht HJ, Slatopolsky, Brown AJ. 25-hydroxyvitamin $D_{3}$ suppresses PTH synthesis and secretion by bovine parathyroid cells. Kidney Int, 2006;70:654-9.

7. Jones $G$. Assay of vitamins $D_{2}$ and $D_{3}$, and 25-hydroxyvitamin $D_{2}$ e $D_{3}$ in human plasma by high-performance liquid chromatography. Clin Chem, 1978;24(2):287-98. 
8. Binkley N, Krueger D, Gemar D, Drezner MK. Correlation among 25hydroxyvitamin D assays. J Clin Endocrinol Metab, 2008;93(5):1804-8.

9. The Vitamin D International External Quality Assessement Scheme (DEQAS). Disponivel em: http://www.deqas.org.

10. Carter GD, Jones JC, Berry JL. The anomalous behaviour of exogenous 25-hydroxyvitamin D in competitive binding assays. J Steroid Biochem Mol Biol, 2007;103:480-2.

11. Glendenning P, Taranto M, Noble JM, Musk AA, Vasikaran SD. Current assays overestimate 25-hydroxyvitamin $D_{3}$ and underestimate 25hydroxyvitamin $\mathrm{D}_{2}$ compared with HPLC: need for assay-specific decision limits and metabolite-specific assays. Ann Clin Biochem, 2006;43:23-30.

12. Silver J, Levi R. Vitamin D supplementation after renal transplantation: how much vitamin D should we prescribe?. Kidney International, 2009;75:94-111.

13. Grant WB e Holick MF. Benefits and Requeriments of Vitamin D for Optimal Health: A Review. Altern Med Rev, 2005; 10(2):94-111.

14. Holick MF. Vitamin D deficiency. N Engl J Med, 2007;357(3):266-81.

15. Webb AR. Review: Who, what, where and when - influences on cutaneous vitamin D synthesis. Prog Biophys Mol Biol, 2006;92:17-25.

16. Lips P. Review: Vitamin D physiology. Progress in Biophysics and Molelucar Biology, 2006;92:4-8. 
17. Heaney RP. The vitamin D requirement in health and disease. J Steroid Biochem Mol Biol, 2005;97:13-19.

18. Need AG, Morris HA, Horowitz M, Nordin BEC. Effects of skin thickness, age, body fat and sunlight on serum 25-hidroxyvitamin D. Am J Clin Nutr, 1993;58:882-5.

19. Tabela Brasileira de Composição de Alimentos (TACO). Disponível em: http://www.unicamp.br/nepa/taco.

20. Saraiva GL, Cendoroglo MS, Ramos LR, Côrrea MP, Castro ML. Influence of ultraviolet radiation on the production of 25 hydroxyvitamin D in the elderly population in the city of São Paulo (2334'S), Brazil. Osteop Int, 2005;198(5):1895-3.

21. Unger MD, Cuppari L, Titan SM, Jorgetti V, Moyses RMA. Vitamin D status in a sunny country: Where has the sun gone? Clin Nutr, 2010; 1-5 (in press).

22. Trivedi DP, Doll R, Khaw KT. Effect of four monthly oral vitamin D3 (cholecalciferol) supplementation on fractures and mortality in men and women living in the community: randomized double blind controlled trial. BMJ, 2003;326:1-6.

23. Lai JK, Lucas RM, Clements MS, Roddan AW, Banks E. Hip fracture risk in relation to vitamin $\mathrm{D}$ supplementation and serum 25 -hydroxyvitamin $\mathrm{D}$ levels: a sistematic review and meta-analyses of randomized controlled trials and observational studies. BMC Public Health, 2010 Jun 11;10:331. 
24. Scragg R, Sowers M, Bell C. Serum 25-hydroxyvitamin D, ethnicity, and blood pressure in the Third National Health and Nutrition Examination Survey. Am J Hypertens, 2007;20(7): 713-9.

25. Pfeifer M, Begerow B, Minne HW, Nachtigall D, Hansen C. Effects of a short-term vitamin $\mathrm{D}(3)$ and calcium supplementation on blood pressure and parathyroid hormone levels in elderly women. J Clin Endocrinol Metab, 2001;86:1633-7.

26. Bhattacharya SK, Ahokas RA, Carbone LD, Newman KP, Weber KT. Macro- and micronutrients in African-americans with heart failure. Heart Fail Rev, 2006;11:45-55.

27. Zittermann A. Review: Vitamin D and disease prevention with special reference to cardiovascular disease. Prog Biophys Mol Biol, 2006;92:3948.

28. Djamali A, Samaniego M, Muth B, Hofmann RM, Becker BN. Review: Medical care of kidney transplant recipients after the first posttransplant year. Clin J Am Soc Nephrol, 2006;1:623-40.

29. National Kidney Foundation: K/DOQI Clinical Practice Guidelines for Bone Metabolism and Disease in Chronic Kidney Disease. Am J Kidney Dis, 2003;42:S1-201.

30. Romão Junior JE. Epidemiologia da doença renal crônica no Brasil2004. Disponível em: www.sbn.org.br/Censo/epidemiologia2004.pps. 
31. Associação Brasileira de Transplante de Órgãos. Estatísticas de transplantes. Período: janeiro a dezembro de 2009. Disponível em: http://www.abto.org.br/abtov02/portugues/populacao/rbt/anoXV_n4/index .aspx.

32. Neves CL. Análise da doença óssea após o transplante renal estável: elevada prevalência de doença mista [tese]. São Paulo, Faculdade de Medicina, Universidade de São Paulo; 2007.

33. Cunninghan J. Post transplantation bone disease. Transplantation, 2005;79:629-34.

34. Vantour LM, Melton LJ, Clarke BL, Achenbach SJ, Oberg AL and McCarthy JT. Long-term fracture risk following renal transplantation: a population-based study. Osteoporosis Int, 2004;160-7.

35. Cruz EAS, Lugon JR, Jorgetti V, Draibe SA e Carvalho AB. Histologic evolution of bone disease 6 months after successful kidney transplantation. Am J Kidney Dis, 2004;44:747-56.

36. Lomonte C, Antonelli M, Vernaglione L, Cazzato F, Chimienti D, Basile C. Are low plasma levels of $250 \mathrm{H}$ vitamin $\mathrm{D}$ a major risk factor for hyperparathyroidism independent of calcitriol in renal transplant patients? Nephrol, 2005;18:96-101.

37. Bhan I, Shah A, Holms J, Wolf M. Post-transplant hypophosphatemia: Tertiary ‘hyper-phosphatoninism’. Kidney Int, 2006;70(8):1486-94. 
38. Boudville NC e Hodsman AB. Renal function and 25-hydroxyvitamina D concentrations predict parathyroid hormone levels in renal transplant patients. Nephrol Dial Transplant, 2006;21:2621-4.

39. Lim WH, Coates PS, Russ GR, Coates PTH. Hyperparathyroidism and Vitamin D deficiency predispose to bone loss in renal transplant recipients. Transplantation, 2009; 8(5): 678-83.

40. Sadlier DM, Magee CC. Prevalence of $25(\mathrm{OH})$ vitamin D (calcidiol) deficiency at time of renal transplantation: a prospective study. Clin Transpl, 2007; 21: 683-8.

41. Stavroulopoulos A, Cassidy MJD, Porter CJ, Hosking DJ, Roe SD. Vitamin D Status in renal transplant recipients. Am J Transpl, 2007; 7: 2546-52.

42. Snellman G, Melthus H, Gedeborg R, Byberg L, Berglund L, Wernroth L, Michaelsson K. Determining vitamin D status: a comparison between commercially available assays. PLoS One, $2010 \mathrm{Jul}$ 13;5(7):e11555.

43. Reichrath J. The challenge resulting from positive and negative effects of sunlight: how much solar UV exposure is appropriate to ballance between risks of vitamin D deficiency and skin cancer? Prog Biophys $\mathrm{Mol}$ Biol, 2006;92: 9-16.

44. Moan J, Porojnicu AC, Dahlback A, Setlow BR. Adressing the health benefits and risks, involving vitamin D or skin cancer, of increased sum exposure. Med Scien, 2008;105(2): 668-73. 
45. Fitzpatrick TB. The validity and practicality of sun-reactive types I through VI. Arch Dermatol, 1988;124(6):869-871.

46. Heaf J, Jakobsen U, Kanstrup IL, Fogh-Andersen N. Dietary habits and nutritional status of renal transplant patients. J Ren Nutr, 2004; 14(1): 2025.

47. Vik T, Try K, Stromme JH. The vitamin D status of man at 70 degrees north. Scand J Clin Lab Invest, 1980; 40: 227-32.

48. Hypponen E and Power C. Hypovitaminosis D in British adults at age 45 $\mathrm{y}$ : nationwide cohort study of dietary and lifestyle predictors ${ }^{1-3}$. Am J Nutr, $2007 ; 85: 860-8$.

49. Cofan F, Vela E, Cleries M and the Catalan Renal Registry. Obesity in renal transplantation: analysis of 2691 patients. Transpl Proc, 2005; 37: 3695-7.

50. Gore JL, Pham PT, Singer JS. Obesity and outcome following renal transplantation. Am J Transpl, 2006; 6: 357-63.

51. Ewers B, Gasbjerg A, Zerahn B, Marckmann P. Impact of vitamin D status and obesity on C-reative protein in kidney-transplant patients. $J$ Ren Nutr, 2008; 18(3): 294-300.

52. Giannini S, Sella S, Realdi G, Bonfante L. Persistent secondary hyperparathyroidism and vertebral fractures in kidney transplantantion: role of calcium-sensing receptor polymorphisms and vitamin D deficiency. J Bone Min Res, 2010;24(4):841-8. 
53. Sezer S, Yavuz D, Canoz MB, Ozdemir FN, Haberal M. Vitamin D status, bone mineral density, and inflammation in kidney transplantation patients. Transpl Proc, 2009; 41: 2823-5.

54. Querings K, Girndt M, Geisel J, Georg T, Tilgen W e Reichrath J. 25-OH vitamin D deficiency in renal transplant recipients. J Clin Endocrinol Metab, 2006;91:526-9.

55. Courbebaisse M, Thervet E, Souberbielle JC, Zuber J, Eladari D, Martinez F, Mamzer-Bruneel MF, Urena P, Legendre C, Friedlander G, Prié D. Effects of vitamin D supplementation on the calcium-phosphate balance in renal transplant patients. Kidney Int, 2009 Mar;75(6):646-51. 